九州大学学術情報リポジトリ

Kyushu University Institutional Repository

\title{
Geomagnetic Pulsations at the Conjugate Stations during the March 9, 1997, Total Solar Eclipse
}

Tanaka, Yoshimasa

Faculty of Sciences, Kyushu University

Tang, $\mathrm{K}$

Department of Space Environment, Institute of Geophysics, Chinese Academy of Science

Yumoto, Kiyofumi

Faculty of Sciences, Kyushu University

Trivedi, N.B.

Instituto Nacional de Pesquisas, Sāo José dos Campos

他

https://doi.org/10.5109/1546093

出版情報: 九州大学大学院理学研究院紀要 : Series D, Earth and planetary sciences. 30 (2)， pp.81-89, 1998-12-28. Faculty of Science, Kyushu University

バージョン :

権利関係 : 
Mem. Fac. Sci., Kyushu Univ., Ser. D, Earth \& Planet. Sci., Vol. XXX, No.2, pp. 81-89, text-figs. 1-6, tables 1-2, December 28, 1998

\title{
Geomagnetic Pulsations at the Conjugate Stations during the March 9, 1997, Total Solar Eclipse
}

\author{
Y.-M. TAnaka, K. TAnG*, K. Yumoto, N. B. Trivedi* ${ }^{*}$, T.-I. Kitamura, \\ and THE CPMN GRouP
}

\begin{abstract}
Pi 2 and Pc 4 geomagnetic pulsations were observed at Mohe (MOH, $L=2.22$ ), China, during the period of the total solar eclipse of March 9, 1997. Polarization analysis was performed on the pulsations with dominant frequencies in the $12.5-25 \mathrm{mHz}$ range. We compared the pulsations observed at Mohe with those at Katanning (KAT, $L=2.13$ ), Australia, which is located near a magnetic conjugate point of Mohe. During the solar eclipse, the orientation of the polarization major axis changed at $\mathrm{MOH}$, however, a similar variation was also observed at KAT. The results indicate that the solar eclipse effect is small for the magnetic pulsations in the $12.5-25 \mathrm{mHz}$ frequency range.
\end{abstract}

\section{Introduction}

The effect of the solar eclipse on the geomagnetic pulsations has been studied since the beginning of the twentieth century. Y. KaTO (1965) reported that the orientation of the polarization major axis of $\mathrm{Pc}_{\mathrm{c}} 3$ pulsations shifted during the solar eclipse, and they explained the result by a special ionospheric current system expected from the decrease of the electrical conductivity in the ionosphere during the solar eclipse. LANZEROTTI et al (1970) reported that there were no significant changes in the orientation of the major axis of the geomagnetic pulsations during the solar eclipse, which was consistent with the small E layer ionization changes measured at the same time. KATO and OKUDA (1956) also presented the decrease of pulsation amplitude during the solar eclipse. However, most of the results were obtained by the observation at one station near the solar eclipse region. Therefore, it has not been clear that these phenomena occurred locally under a condition of the solar eclipse.

We participated in the observations of the total solar eclipse at Mohe ( $\mathrm{MOH}, L=2.22$ ), China, on March 9, 1997. The solar eclipse effect on the magnetic field was surveyed by using a fluxgate magnetometer during the period of solar eclipse. Furthermore, data from the Circum-pan Pacific Magnetometer Network (CPMN) are used to investigate the spatial structure of the solar eclipse effect. The CPMN project is being conducted by Kyushu University since 1996 as a newly integrated network, which consists of the $210^{\circ} \mathrm{MM}$ Magnetometer Network (Yumoto et al., 1996) and the Equatorial Magnetometer Network (TACHIHARA et al., 1996). Katanning (KAT, $L=2.13$ ), Australia, is particularly focused, because it is located near a magnetic conjugate point of Mohe. The data from another pair

\footnotetext{
Manuscript received August 31, 1998; accepted October 7, 1998.

* Department of Space Environment, Institute of Geophysics., Chinese Academy of Science, Beijing, China

** Instituto Nacional de Pesquisas, Sāo José dos Campos, SP, Brazil
} 


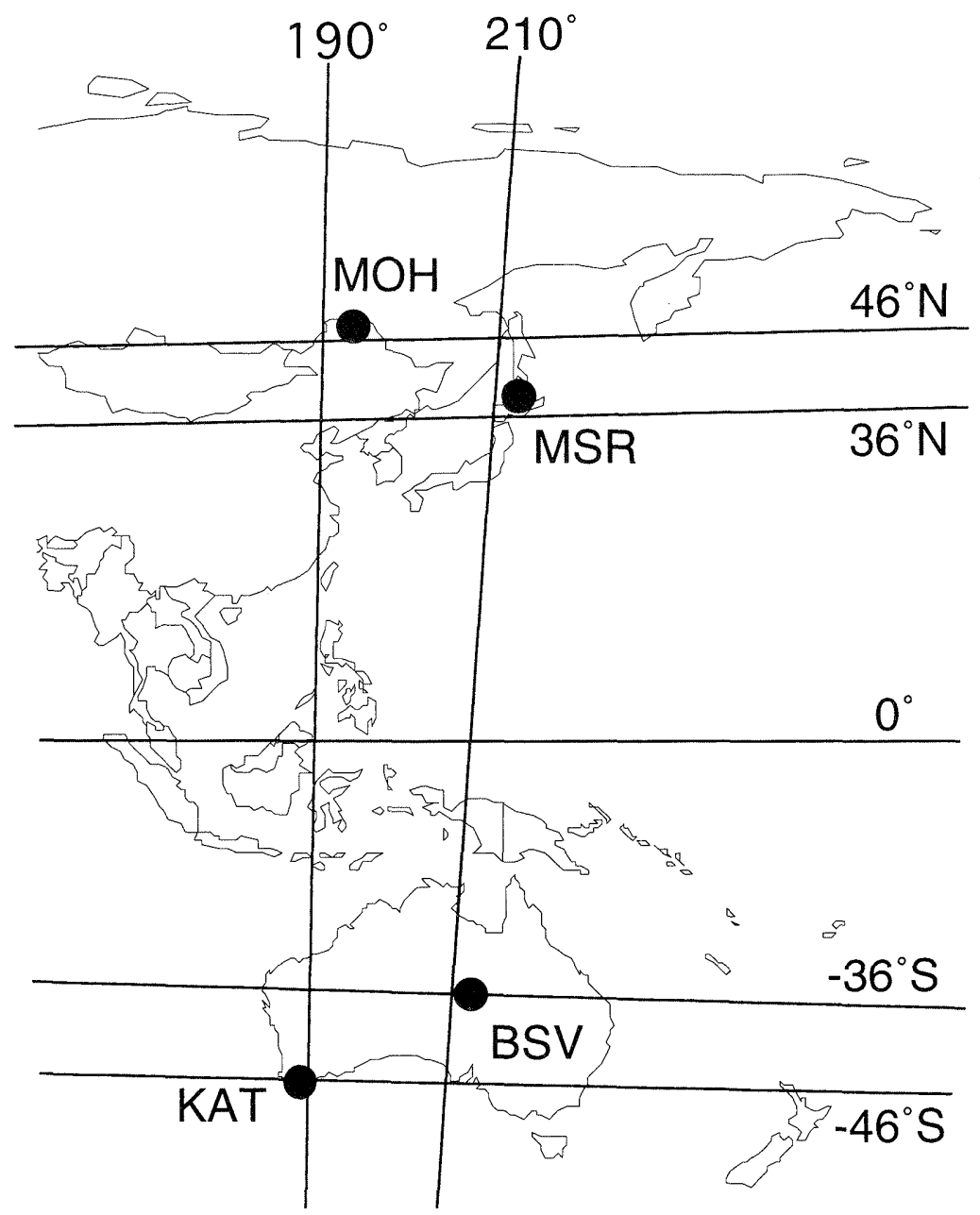

Fig 1. Station locations of Mohe (MOH), where the total solar eclipse occurred on March 9, 1997, and the Circum-pan Pacific Magnetometer Network array. The horizontal and vertical lines show the geomagnetic latitude and longitude, respectively. KAT is located near the magnetic conjugate point of $\mathrm{MOH}$. MSR and BSV are another pair of magnetic conjugate stations.

of conjugate stations at lower latitude, Moshiri (MSR, $L=1.61$ ), Japan, and Birdsville (BSV, $L=1.56$ ), Australia, are analyzed to compare with results from a pair of $\mathrm{MOH}$ and KAT. The sampling times of magnetometers are $1 \mathrm{~s}$ at all the stations. The magnetometer digitization step is $0.037 \mathrm{nT}$ at MOH and KAT, and $0.015 \mathrm{nT}$ at MSR, BSV. The locations and coordinates of these stations are presented in Fig. 1 and Table 1.

Fig. 2 shows the daily variations of the $H$ (top) and $D$ (bottom) components of the magnetic field observed at these four stations on March 9, 1997. We define LT at MOH as $\mathrm{UT}+8 \mathrm{hr}$. Vertical lines indicate the time interval of the solar eclipse observed at MOH. The magnetic activity of the day is relatively quiet $(K P=-1 \sim+2)$. It should be noticed that large artificial noise can be seen at MSR. Fig. 3 shows the amplitude time records of 
Geomagnetic Pulsations at the Conjugate Stations

during the March 9, 1997, Total Solar Eclipse

Table 1. Coordinates of stations.

\begin{tabular}{|c|c|c|c|c|c|c|}
\hline \multirow{2}{*}{$\begin{array}{l}\text { Station Name } \\
\text { Mohe }\end{array}$} & \multirow{2}{*}{$\begin{array}{c}\begin{array}{c}\text { Abbrevi- } \\
\text { ation }\end{array} \\
\mathrm{MOH}\end{array}$} & \multicolumn{2}{|c|}{ Geographic } & \multicolumn{2}{|c|}{$\begin{array}{c}\text { Geomagnetic } \\
\text { Latitude } \\
\text { Longitude }\end{array}$} & \multirow{2}{*}{$\begin{array}{c}\mathrm{L} \\
2.22\end{array}$} \\
\hline & & 53.29 & 122.23 & 47.45 & 194.73 & \\
\hline Moshiri & MSR & 44.37 & 142.27 & 37.32 & 213.47 & 1.61 \\
\hline Birdsville & BSV & -25.54 & 139.21 & -36.09 & 213.18 & 1.56 \\
\hline Katanning & KAT & -33.68 & 117.62 & -46.37 & 188.44 & 2.13 \\
\hline Eusebio & EUS & -3.85 & -38.42 & 0.09 & 34.74 & 1.00 \\
\hline
\end{tabular}

Raw Data

a) H-comp. (1997/03/09) 20nT/Div

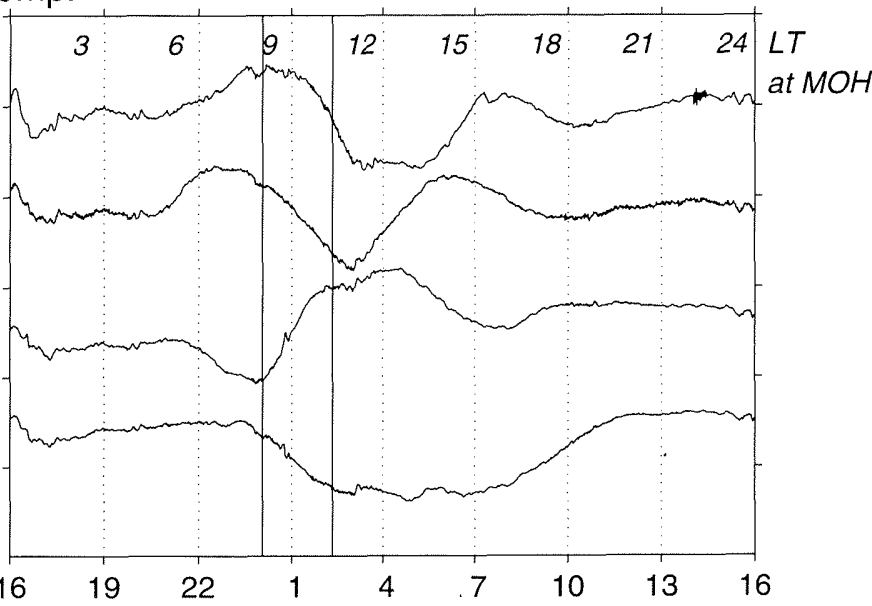

b) D-comp.

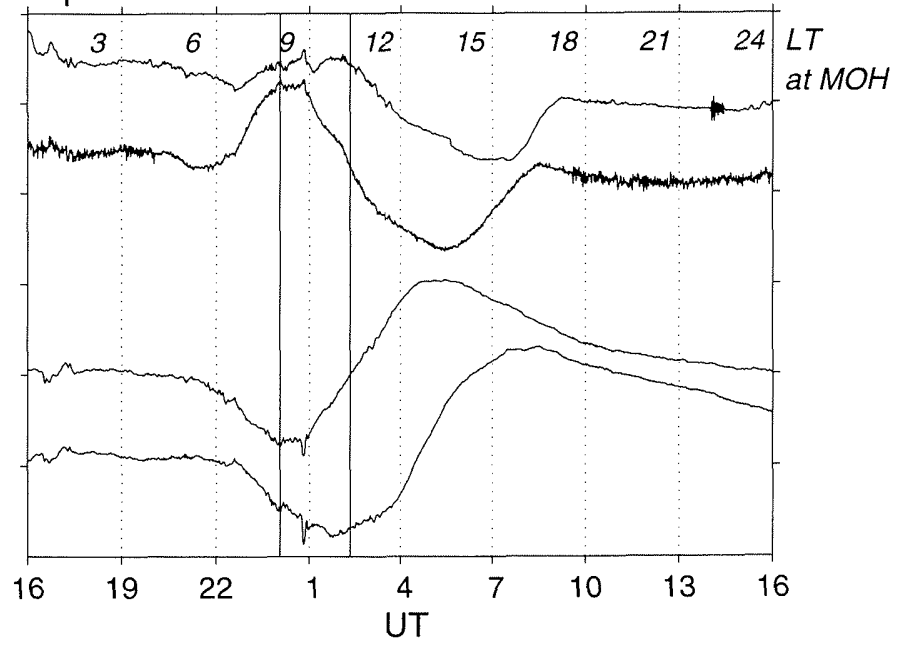

Fig 2. $H$ (a) and $D$ (b) component variations of magnetic field observed at $\mathrm{MOH}, \mathrm{MSR}, \mathrm{BSV}$, and KAT. Vertical lines indicate a time interval of the solar eclipse observed at $\mathrm{MOH}$. 


\section{Filtered Data (40-150s)}
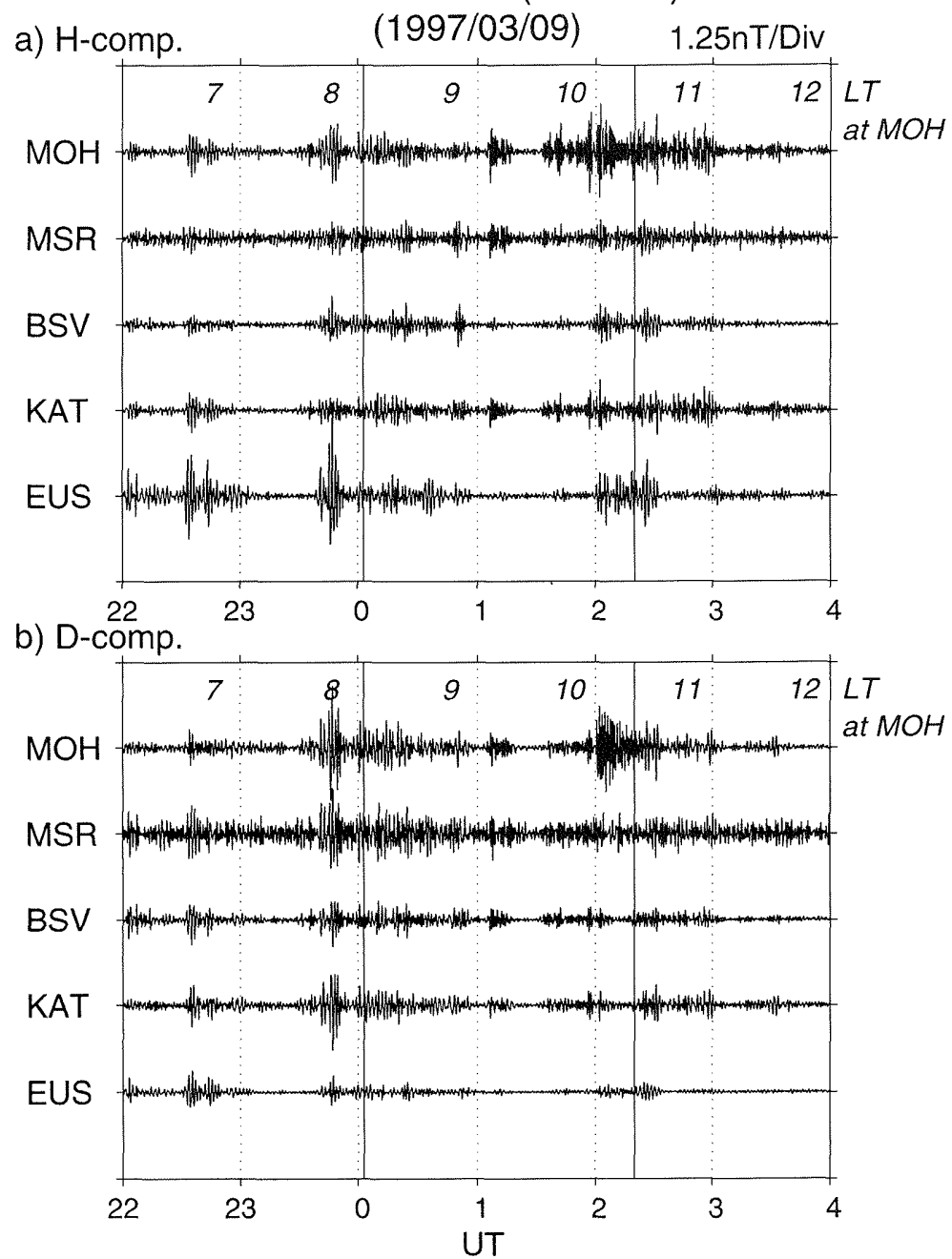

Fig 3. Band pass filtered (40 to $150 \mathrm{~s}$ ) plots of the $H$ (a) and $D(\mathrm{~b})$ components during the period from 0600 to $1200 \mathrm{LT}$. LT is defined as UT $+8 \mathrm{hr}$ at MOH. Eusebio (EUS), which is located on the dip equator around the midnight, is added to find Pi 2 pulsations related to the substorm onset. Vertical lines show a time interval of the solar eclipse observed at MOH.

band-pass filtered data (40-150s). In order to confirm that these pulsations were related to the substorm, we use data from Eusebio (EUS, $L=1.00$ ), Brazil, which is located on the dip equator around the local midnight (2130-2400 LT) during the period of the solar eclipse. By a visual scan of the filtered data, three $\mathrm{Pi} 2$ events related to a substorm onset at 0630, 0735, and $1000 \mathrm{LT}$ and three Pc 4 pulsations at 0905-0920, 0930-1000, and 1030-1130 LT were found. The event observed at 0800-0900 LT is Pi 2 and/or Pc 4 pulsation that may be related to the substorm. All the events are listed in the Table 2, together with their observation time, and dominant frequencies. In the next section, we investigate the behavior of these Pi 2 and Pc 
Table 2. Geomagnetic pulsation events observed around the period of the total solar eclipse.

\begin{tabular}{cccc}
\hline $\begin{array}{c}\text { Event } \\
\text { Number }\end{array}$ & $\begin{array}{c}\text { Start } \\
\text { Time }\end{array}$ & $\begin{array}{c}\text { Pulsation } \\
\text { Type }\end{array}$ & $\begin{array}{c}\text { Dominant } \\
\text { Frequencies }\end{array}$ \\
\hline 1 & $0630 L T$ & $P i 2$ & $10,22 m \mathrm{mz}$ \\
2 & $0735 L T$ & $P i 2$ & $9,22 \mathrm{mHz}$ \\
3 & $0800 L T$ & Pi2orPc4 & $9,22 \mathrm{mHz}$ \\
4 & $0905 L T$ & $P c 4$ & $17 \mathrm{mHz}$ \\
5 & $0930 L T$ & $P c 4$ & $14 \mathrm{mHz}$ \\
6 & $1000 L T$ & $P i 2$ & $?$ \\
7 & $1030 L T$ & $P c 4$ & $12,20 \mathrm{mHz}$ \\
\hline
\end{tabular}

4 pulsations at the magnetic conjugate stations.

\section{Polarization characteristics of Pi 2 and Pc 4 pulsations}

We first calculated a power spectral density of the horizontal components by using the fast Fourier transform (FFT) method in order to determine the dominant frequencies of each event. Prior to the FFT analysis, the data were band-pass filtered in the $10-600$ s period range and they were reduced to 3 -second sampling (Nyquist frequency $=167 \mathrm{mHz}$ ). A time window

\section{Hodogram}

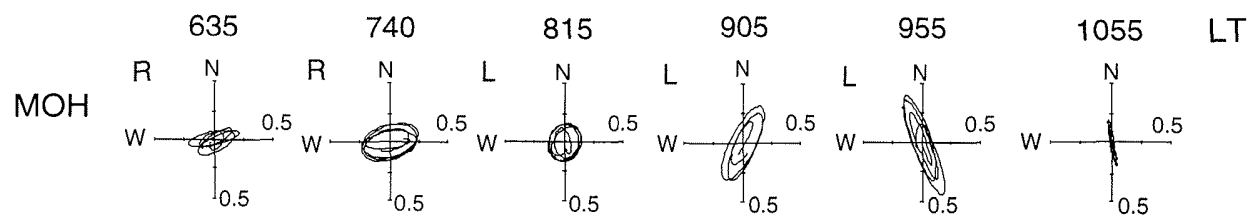

MSR
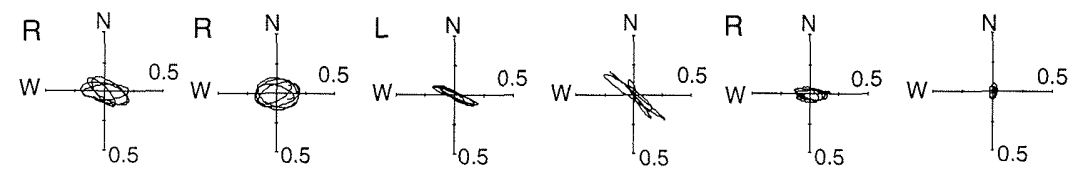

BSV

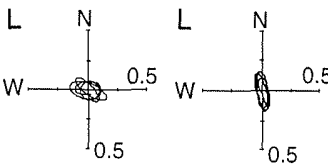

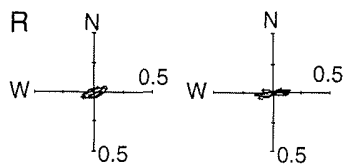

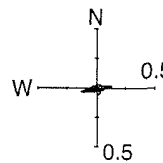<smiles>CC([13CH3])(N)N</smiles>

KAT<smiles></smiles>

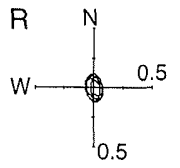

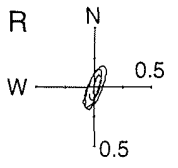

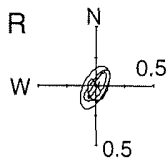

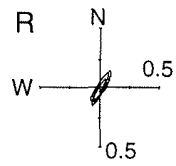

Fig 4. Hodograms in the $H-D$ plane of the pulsations observed at four stations on March 9. $\mathrm{R}$ and $\mathrm{L}$ indicate right-handed and left-handed sense of polarization, respectively. Arrow at the bottom means the interval of the solar eclipse. 
of 256 points $(12.8 \mathrm{~min})$ was shifted by $10 \mathrm{~min}$, and the power spectral density was averaged over the duration of Pi 2 or Pc 4 pulsations. From the power spectral density, two main spectral peaks were found in many of the events; one is in the $12.5-25 \mathrm{mHz}$ ( $\mathrm{T}=40-80 \mathrm{~s}$ ) frequency range and the other is in the $6.6-12.5 \mathrm{mHz}(\mathrm{T}=80-150 \mathrm{~s})$ range. The dominant frequencies of each event are listed in Table 2. In particular, we focus on the $12.5-25 \mathrm{mHz}$ frequency range, because the events cover the time interval around the totality of the solar eclipse.

Hodograms in the $H-D$ plane at four stations are drawn in Fig. 4. Arrow at the bottom indicates the time interval of the solar eclipse from the first contact at $0803 \mathrm{LT}$ to the last contact at $1019 \mathrm{LT}$. The middle eclipse (co-centers of the sun and moon) at $0910 \mathrm{LT}$ is shown as cross ( $\mathrm{x}$ ). The notations, $\mathrm{R}$ and $\mathrm{L}$, means right-hand and left-hand sense of polarization, respectively. The first thing to be noticed is that most of the events exhibit a mirror relation at the magnetic conjugate stations, $\mathrm{MOH}$ and KAT. Before the solar eclipse, the major axes of polarization are in the NE-SW quadrant at $\mathrm{MOH}$ and in the NW-SE quadrant at KAT. Their senses of polarization are right-handed in the northern hemisphere and left-handed in the southern hemisphere. The sense of polarization reverses in both hemispheres across 0800 $\mathrm{LT}$ (from $\mathrm{R}$ to $\mathrm{L}$ in the northern hemisphere and from $\mathrm{L}$ to $\mathrm{R}$ in the southern hemisphere). When the Pc 4 event started at $0930 \mathrm{LT}, \mathrm{MOH}$ showed a change of the orientation of the

\section{7/03/09}

(frequency $=12.5-25 \mathrm{mH}$ )

\section{Amplitude Ratio (MOH/KAT)}
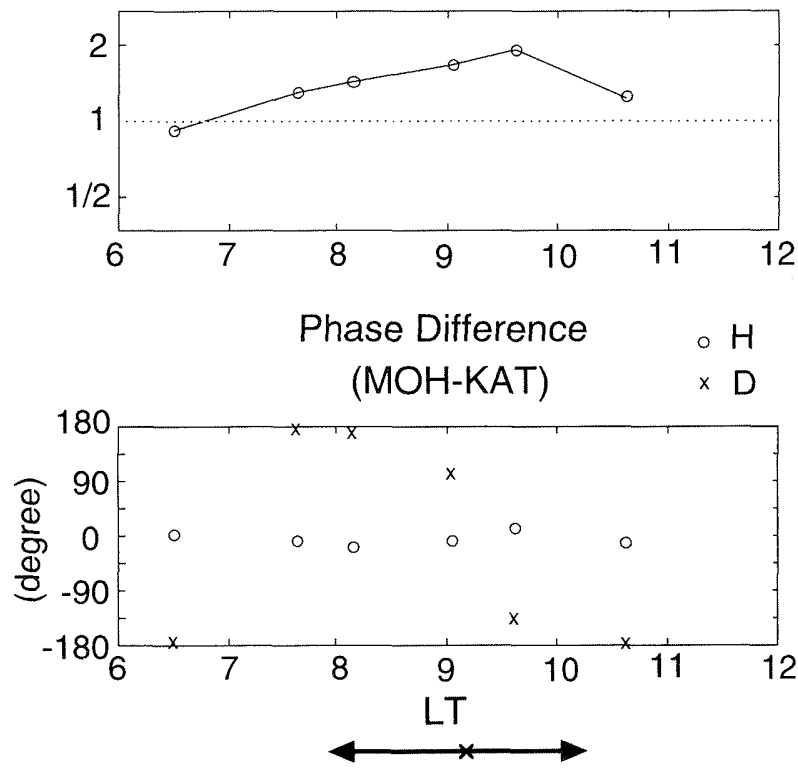

Fig 5. Top panel shows a time variation of the amplitude ratio (MOH /KAT) of the pulsations observed on March 9. Phase difference between $\mathrm{MOH}$ and KAT is presented in the bottom panel. A positive (negative) sign means that the signal at MOH leads (lags) that at KAT. 
major axis from NE-SW to NW-SE, however, the mirror relation was kept between $\mathrm{MOH}$ and KAT. The mirror relation was broken only for the Pc 4 event at $0905 \mathrm{LT}$ just before the totality of the solar eclipse. The hodograms of another pair of conjugate stations, MSR and BSV, also show the mirror relation even for the Pc 4 event at $0905 \mathrm{LT}$, however, MSR contains a large noise as seen in Fig. 3.

Top panel of Fig. 5 shows the amplitude ratio of $\mathrm{Pi} 2$ and $\mathrm{Pc} 4$ pulsations between $\mathrm{MOH}$ and KAT. The amplitude ratio was calculated as $\sqrt{\mathrm{P}_{H+D}(\mathrm{MOH}) / \mathrm{P}_{H+D}(\mathrm{KAT})}$, where $\mathrm{P}_{H+D}$ denotes the sum of power spectral density of both the $H$ and $D$ components. The time interval of the solar eclipse is shown as the arrow again. With regard to Pi 2 pulsations observed at 0630 LT near sunrise, the amplitude ratio is nearly 1 . After the sunrise, the amplitude ratio gradually increases until $0940 \mathrm{LT}$, when the amplitude ratio is maximum (1. 92). After the solar eclipse finished, the amplitude ratio decreased to 1.25 at $1030 \mathrm{LT}$. Phase difference of the $H$ and $D$ components between $\mathrm{MOH}$ and KAT is presented in the bottom panel of Fig. 5. A positive (negative) sign means that the signal at $\mathrm{MOH}$ leads (lags) that at KAT. All events show an in-phase relation in the $H$ component and an out-of-phase relation in the $D$ component, except for the Pc 4 pulsation observed at $0905 \mathrm{LT}$ just before the totality of the solar eclipse. The $90^{\circ}$ phase difference in the $D$ component at $0905 \mathrm{LT}$ corresponds to the destruction of the mirror relation between $\mathrm{MOH}$ and KAT.

We also analyzed the events that have dominant frequencies in the $6.6-12.5 \mathrm{mHz}(\mathrm{T}=$

\section{$1997 / 03 / 10$}

(frequency $=12.5-25 \mathrm{mH}$ )

\section{Amplitude Ratio (MOH/KAT)}
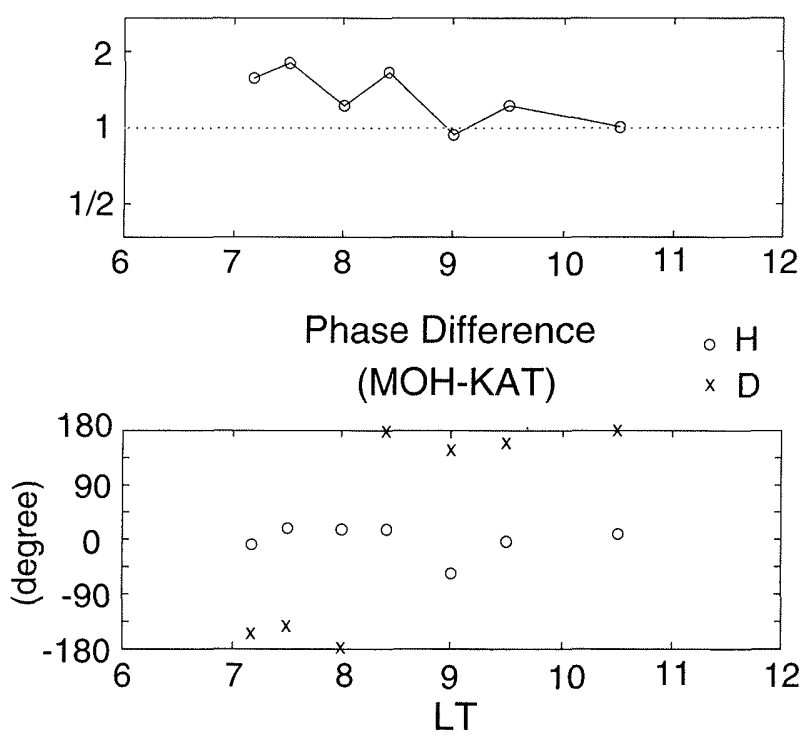

Fig 6. Time variation of the amplitude ratio (top) and phase difference (bottom) between $\mathrm{MOH}$ and KAT, with respect to Pc3 pulsations observed on March 10. 
$80-150$ s) range. The results are not displayed here, because there is no events in this frequency range during the period of the solar eclipse. Furthermore, we analyzed the data obtained on March 10 to identify if the results were caused by the solar eclipse effect or not. Fig. 6 shows the amplitude ratio and phase difference between MOH and KAT, with respect to Pc 3 pulsations observed on March 10. The amplitude ratio shown in the top panel is equal to or larger than 1 in the interval from 0700 to $1030 \mathrm{LT}$, which is similar to Fig. 5. For the phase difference in the bottom panel, in-phase relation of the $H$ component and out of phase relation of the $D$ component indicate the mirror relation between $\mathrm{MOH}$ and KAT.

\section{Summary and Discussion}

The major results can be summarized as follows:

1, The dayside Pi 2 and Pc 4 pulsations were observed prior to and during the period of the solar eclipse on March 9, 1997.

2, All the events showed a mirror relation between the magnetic conjugate stations, $\mathrm{MOH}$ and KAT, except for one event. The mirror relation was broken only for the Pc 4 event at 0905 LT just before the totality of the solar eclipse.

3 , The amplitude of the pulsations at $\mathrm{MOH}$ was larger than that at KAT during the solar eclipse. A similar tendency was also seen on March 10.

Under the condition of the solar eclipse, the electrical conductivity of the ionosphere is expected to change because of the decrease of the ionization in the E layer. RAMASASTRY and Schimid (1970), and KLobuchar and MALiK (1970) reported that the decrease in total ionosphere electron content during the eclipse was approximately a factor of 3 . The change of the electrical conductivity affects an ionospheric current system of the geomagnetic pulsations (Y. KATO, 1963). Therefore, the orientation of the major axis of polarization can change during the period of the solar eclipse. The major axis and sense of polarization apparently varied at $\mathrm{MOH}$ during the solar eclipse (Fig. 4). However, the variation was also recognized at the magnetic conjugate station, KAT. Yumoto et al. (1988) reported that the low-latitude Pc 3 pulsations show the mirror relation between the magnetic conjugate stations, and their major axis orientations change abruptly across the local noon. Therefore, the change of the major axis orientation during the period of the solar eclipse can be interpreted as the local time variation that occurred independently of the solar eclipse. The destruction of the mirror relation occurred only for one case of Pc 4 event detected just before the totality of the solar eclipse. It is not clear whether it was caused by ionospheric conductivity effect.

The result 3 may be related to the decrease of the conductivity of the ionosphere during the period of solar eclipse. The decrease of the conductivity weakens the shielding effect of the ionosphere, so the large energy of pulsations coming from the magnetosphere can penetrate through the ionosphere. However, it must be noted that the events consist of two kinds of pulsations. Pc 4 pulsations are generally believed to be standing Alfvén mode waves excited by the field line resonance, so the pulsations should have larger amplitudes at $\mathrm{MOH}$ during the period of the solar eclipse due to the weaker shielding effect of the ionosphere. This idea is consistent with the result 3 . On the other hand, there are some explanations for the dayside Pi 2 pulsations at low latitudes, including an instantaneous horizontal transmission of electromagnetic signals from the nightside ionosphere (S. FuJiTA, personal communication, 1998). At present, it is not clear how the decrease of the electrical conductivity of the 
ionosphere at the solar eclipse point affects on the amplitude of Pi 2 pulsations.

However, a similar amplitude ratio was seen on March 10, 1997. Thus, we conclude that the effect of the solar eclipse on the amplitude of pulsations is quite small. Recently, computations of northern/southern asymmetry of Pc 3-5 pulsations were performed by YoshrKaWA (1997). He shows that the amplitude of the pulsations with the period of $50 \mathrm{~s}$ is larger in the northern hemisphere than in the southern hemisphere in the vernal equinox. This result is caused by the fact that the intensity of the ambient magnetic field is smaller in the northern hemisphere than in the southern hemisphere. We speculate that the larger amplitude at $\mathrm{MOH}$ attributes to the northern/southern asymmetry of pulsations. A statistical analysis of the data obtained at $L \sim 2$ is needed to confirm the northern/southern asymmetry.

\section{Acknowledgments}

Our sincere thanks go to the IGP solar eclipse team, Chinese Academy of Sciences, and all members of the CPMN Project.

\section{References}

Kato, Y. (1965): The effect on the magnetic micropulsation of the solar eclipse of 20 July 1963. Sci. Rep. Tohoku Univ., [Geophys.], 16, 49.

Kato, Y., and M. OKudA (1956): The effect of the solar eclipse on the rapid pulsations of the earth's magnetic field. Sci. Rep. Tohoku Imp. Univ., [Geophys.], 7, 37.

Klobuchar, J. A., and C. Malik (1970): Comparison of changes in total electron content along three paths. Nature, 226, 1113.

Lanzerotti, L. J., C. G. Maclennan, L. V. Medford, and N. A. Tartaglia (1971): Midlatitude geomagnetic pulsations during the March 7, 1970, solar eclipse. J. Geophys. Res., 76, 3684.

RAMASAstry, J., and P.E. SchmidT. JR. (1970): Electron content measurements during the March 7, 1970. solar eclipse (abstract), Trans. AGU, 51, 785.

Tachimara, H., M. Shinohara, M. Shimoizumi, O. Saka, and T. Kitamura (1996): Magnetometer system for studies of the equatorial electrojet and micropulsations in equatorial regions. $J$. Geomag. Geoelectr., 48, 1311.

YoshiKawa, A. (1997): Studies on the ionospheric divergent Hall current. PhD thesis, Dept. of Earth and Planetary Sci., Kyushu University, Fukuoka, Japan, 89-110.

Yumoto, K., T. Sarto, Y. Tanaka, K.J.W. Lynn, F.W. Menk, and B.J.Fraser (1988): Polarization and amplitude characteristics of $\mathrm{Pc} 3$ pulsations in conjugate area around $\mathrm{L}=1.3-2.1$. J. Geophys. Res., 93, 7386.

Yumoto, K., and The 210 MM Magnetic Observation Group (1996): The STEP 210 magnetic meridian network project. J. Geomag. Geoelectr., 48, 1297. 